\title{
Validity and reliability of the self-rated fall risk questionnaire in older adults with osteoporosis
}

\author{
Nitchanant Kitcharanant, Ekasame Vanitcharoenkul and Aasis Unnanuntana* (i)
}

\begin{abstract}
Background: Several risk assessments have been developed to evaluate fall risk in older adults, but it has not been conclusively established which of these tools is most effective for assessing fall risk in this vulnerable population. Recently, the U.S. Centers for Disease Control and Prevention (CDC) developed the self-rated Fall Risk Questionnaire (self-rated $\mathrm{FRQ}$ ), a 12-item questionnaire designed to screen older adults who are at risk of falling and has been widely used in many centers. This study aimed to determine the validity and reliability of the self-rated FRQ in older adults with osteoporosis.

Methods: This prospective study was conducted at the Department of Orthopedic Surgery, Faculty of Medicine Siriraj Hospital, Mahidol University, Bangkok, Thailand from December 2019 to March 2020. Sixty-eight men or postmenopausal women aged $>65$ years who were diagnosed with osteoporosis either by bone mineral density Tscore or by occurrence of fragility fracture were evaluated with the self-rated $F R Q$, the Thai falls risk assessment test (Thai-FRAT), the timed get-up-and-go test (TUG test), the Berg Balance Scale (BBS), and the 5 times sit-to-stand test (5TSTS test). Validity of the self-rated FRQ was assessed by evaluating the correlations ( $r$ ) between the self-rated FRQ score and the scores from the other four assessments. Reliability of the self-rated FRQ was evaluated by measuring test-retest reliability and internal consistency.

Results: The self-rated FRQ was moderately strongly correlated with the BBS, TUG test, and 5TSTS test $(r=$ 0.535 to $0.690 ; p<0.001)$, and fairly correlated with the Thai-FRAT $(r=0.487 ; p<0.001)$. Test-retest reliability of the self-rated FRQ was high, with a Kappa of 1. Internal consistency of the self-rated FRQ was excellent (Cronbach's alpha: 0.936).

Conclusions: The self-rated FRQ was found to be a valid and reliable tool for evaluating fall risk in older adults with osteoporosis. Since assessment of fall risk requires a multifaceted measurement tool, the selfrated $F R Q$ is an appropriate tool that can be integrated into the fall risk assessment algorithm in older adults with osteoporosis.
\end{abstract}

Keywords: Validity, Reliability, Self-rated fall risk questionnaire, Older adults, Osteoporosis

\footnotetext{
* Correspondence: uaasis@gmail.com

Department of Orthopedic Surgery, Faculty of Medicine Siriraj Hospital,

Mahidol University, 2 Wanglang Road, Bangkoknoi, Bangkok 10700, Thailand
}

(c) The Author(s). 2020 Open Access This article is licensed under a Creative Commons Attribution 4.0 International License, which permits use, sharing, adaptation, distribution and reproduction in any medium or format, as long as you give appropriate credit to the original author(s) and the source, provide a link to the Creative Commons licence, and indicate if changes were made. The images or other third party material in this article are included in the article's Creative Commons. licence, unless indicated otherwise in a credit line to the material. If material is not included in the article's Creative Commons licence and your intended use is not permitted by statutory regulation or exceeds the permitted use, you will need to obtain permission directly from the copyright holder. To view a copy of this licence, visit http://creativecommons.org/licenses/by/4.0/ The Creative Commons Public Domain Dedication waiver (http://creativecommons.org/publicdomain/zero/1.0/) applies to the data made available in this article, unless otherwise stated in a credit line to the data. 


\section{Introduction}

Osteoporosis is a silent and progressive skeletal disorder that is characterized by low bone mineral density and deterioration of bone micro-architecture [1]. As more societies around the world become aging or aged societies, the incidence of osteoporosis and its most serious complication, fragility fracture, are also increasing [2]. Osteoporotic patients are known to have decreased muscle strength, postural changes, and poor body balance, which collectively can lead to an increased risk of falls $[3,4]$. Fragility fracture usually occurs after a simple fall, and subsequently leading to increased disability, morbidity, and mortality [5]. A previous study reported a $25 \%$ mortality rate among fall-related hip fracture patients aged over 65 years [6]. Among those who have already sustained a fragility hip fracture, there is a high probability of a second fall and a second fracture [7]. Therefore, a reliable tool for assessing fall risk in older adults with osteoporosis is urgently needed.

Although a number of risk assessment tools have been developed to evaluate fall risk in older adult populations $[8,9]$, it remains controversial which of these tools is the optimal assessment for fall risk. Some fall risk assessment tools ask the patient to perform specific tasks, such as the timed get-up-and-go test (TUG test) and the Berg Balance Scale (BBS). However, these performance-based tests are difficult to routinely administer in an outpatient setting. Recently, the U.S. Centers for Disease Control and Prevention $(\mathrm{CDC})$ developed the self-rated Fall Risk Questionnaire (self-rated FRQ), a 12-item questionnaire designed to screen older adults who are at risk of falling, and is a component of the STEADI toolkit, which provides patient and health care provider fall prevention education materials [10].

The self-rated FRQ has been shown to have good concurrent validity [11], and has been widely used in many centers. Although a Thai language translation of the self-rated FRQ has been validated, the study only included community-dwelling older adults. No such validation of this tool has been performed in older Thai adults with osteoporosis, therefore, the objectives of this study were to develop the Thai self-rated FRQ, and to test its validity and reliability in older Thai adults with osteoporosis.

\section{Methods}

The study protocol and consent form were both approved by the Siriraj Institutional Review Board (SIRB) of the Faculty of Medicine Siriraj Hospital, Mahidol University, Bangkok, Thailand (COA no. Si 749/2019). This study was conducted in accordance with the principles described in the Declaration of Helsinki and all of its later amendments. The original English language version of the self-rated FRQ was translated into Thai language using a forward-backward translation technique according to guidelines proposed by Beaton et al. [12]. This process involves two translations of the self-rated FRQ from English to Thai, one by a professional English translator and one by a bilingual physician. The two translations were then reviewed and adapted into one version. Backward translation from Thai into English was performed by a local professional translator who had no access to or awareness about the original selfrated FRQ. The backward version was then compared to the original English self-rated FRQ to identify any discrepancies. This process resulted in the development of the final version. Afterwards, a group of experts in falls in older adults with osteoporosis that consisted of 2 orthopedic surgeons, 1 physiatrist, 1 geriatrician, and 1 fracture liaison service nurse were asked to evaluate the content validity of the self-rated FRQ. Each expert was asked to rate each item on the self-rated FRQ with a score of 1 (agree), 0 (unsure/ unclear), or - 1 (disagree) to evaluate the content validity. The average score of each questionnaire item was then used to calculate the index of item-objective congruence. We affirmed the understandability of the questions by exposing 15 randomly selected osteoporotic patients to the self-rated FRQ as the final step of the translation protocol.

\section{Validation \\ Patients}

The authors prospectively enrolled patients from the outpatient orthopedic unit of the Department of Orthopedic Surgery, Faculty of Medicine Siriraj Hospital, Mahidol University, Bangkok, Thailand from December 2019 to March 2020. We included men and postmenopausal women aged more than 65 years who were diagnosed with osteoporosis by bone mineral density (BMD) T-score $\leq-2.5$ or by history of low-energy hip or vertebral compression fracture (VCF). Patients with severe cognitive and/or neurological impairment (e.g., dementia), deafness, or severe cardiopulmonary diseases for whom it would not be safe to undergo performancebased testing were excluded. All included patients were evaluated by the same investigator (NK). Data, including age, gender, body mass index, Charlson comorbidity index, type of surgery, pre-injury walking status, and living condition, were collected and recorded. Written informed consent was obtained from each patient who participated in this study.

\section{Outcome measurement tools}

Each participant was asked to complete the self-rated FRQ and the Thai Falls Risk Assessment Test (ThaiFRAT). Participants were also asked to perform the 3 following performance-based tests: BBS, TUG test, and the 5 times sit-to-stand test (5TSTS test). To determine 
the test-retest reliability of the self-rated FRQ, a second copy of the self-rated FRQ was provided to the first 30 patients in a stamped, self-addressed envelope. One week later, those patients were reminded by telephone to complete the provided second copy of the self-rated FRQ, and to return it by Thailand Post to the research team.

\section{Self-rated fall risk questionnaire (self-rated $\mathrm{FRQ}$ )}

The self-rated FRQ, which is the fall risk screening component of the STEADI algorithm [13], comprises 12 questions specific to individual physical functional performance and different fall risk factors. Each question can be scored as 0 or 1 , or 0 or 2 depending on the question, and the total possible score is 14. A higher score indicates a higher risk of falling. The original version of the self-rated FRQ was shown to have good validity and reliability for evaluating older adult patients who are at high risk of falling with a cutoff value of 4 $[11,14]$. If a patient scored 4 points or more, their fall risk was considered to be increased.

\section{Thai falls risk assessment test (Thai-FRAT)}

Thai-FRAT is a fall risk assessment tool that was developed by a group of Thai investigators in 2008 to assess fall risk in Thai community-dwelling older adults. It consists of 6 items that identify fall risk factors, including gender, visual impairment, balance impairment, medication use, history of falls, and type of residence. The scoring range varies according to the item for a possible total score of 11 . Thai-FRAT has good validity and reliability for identifying older adult patients who are at high risk for falling with a cutoff value of 4 [15]. If a patient scored 4 points or more, their fall risk was considered to be increased.

\section{Berg balance scale (BBS)}

BBS is a performance-based test that asks patients to perform 14 tasks that are used to assess patient balance. Each task has a 5-point scale with a scoring range from 0 to 4 for a maximum total score of 56 . A lower score indicates higher risk for falls. BBS has good validity and reliability for identifying older adult patients who are at high risk for falls with a cutoff value of 45 [16]. If a patient scores less than 45 points, their fall risk was regarded as being increased.

\section{Timed get-up-and-go test (TUG test)}

Patients were asked to stand up from a high-seated chair, walk to a mark $3 \mathrm{~m}$ away at a comfortable pace, and then return to a sitting position [17]. Patients were allowed to use their arms when getting up from or sitting down in the seat. Patients were asked to perform this task three times, and the average time to complete the test was calculated and recorded. TUG test was reported to be a reliable tool for identifying risk of falls among older adult patients [18]. A threshold of $12 \mathrm{~s}$ was used as the cutoff value for detecting older adult patients at high risk for falling [18]. If patients took $12 \mathrm{~s}$ or longer to perform the TUG test, they were considered to be at possible risk of falling.

\section{5 times sit-to-stand test (5TSTS test)}

The 5TSTS test was conducted by asking patients to sit upright in an armless chair with a seat height of $43 \mathrm{~cm}$ with their arms crossed across their chest. The evaluator started timing after speaking the word "go", after which patients stand up from a chair (without pushing off) and sit back down 5 times as quickly as possible. Timing stopped when the patients' buttocks reached the chair after completing the fifth stand up-sit down cycle [19]. The current evidence demonstrates the efficacy of the 5TSTS for determining risk of falls in older adult patients with a cutoff value of $15 \mathrm{~s}$ [20]. If patients took longer than $15 \mathrm{~s}$ to perform the 5TSTS test, they were classified as being at higher risk of falling.

\section{Data analysis}

Data analyses were performed using SPSS Statistics version 18 (SPSS, Inc., Chicago, IL, USA). KolmogorovSmirnov test was used to assess the distribution of data. Content validity of the self-rated FRQ was determined using the index of item-objective congruence. Construct validity was evaluated by comparing scores from the self-rated FRQ with scores from the BBS, Thai-FRAT, TUG, and 5TSTS tests. Construct validity was determined using chi-square test and Spearman's rank correlation coefficient. A Spearman's rank correlation coefficient $(r)$ of $<0.3$ was considered poor; 0.3 to 0.5 , fair; $>0.5$ to 0.8 , moderately strong; and, $>0.8$, very strong [21]. Since osteoporosis can be diagnosed using BMD T-score or by the occurrence of a fragility fracture, osteoporotic patient with a history of fragility fracture may have different characteristics when compared to those without fracture. Therefore, we have further evaluated construct validity in these two subgroup populations.

Test-retest reliability of the self-rated FRQ was also tested using Kappa statistics. A Kappa value of 0.1 to 0.2 was considered slight; 0.21 to 0.4 , fair; 0.41 to 0.6 , moderate; 0.61 to 0.8 , substantial; and $>0.8$, almost perfect $[21,22]$. Internal consistency of the self-rated FRQ was assessed using Cronbach's alpha. A Cronbach's alpha within the range of 0.8 to 0.9 was considered good, and a value $\geq 0.9$ was considered excellent [23]. The distribution of scores was calculated to evaluate for ceiling and floor effect. A ceiling or floor effect was considered to 
exist if $>15 \%$ of subjects achieved the lowest or highest possible score [23].

The sample size was estimated based on correlation between two tests. We assumed that the self-rated FRQ had very good correlation with BBS $(|r|$, absolute $r=$ 0.75). Using a 2-sided type I error of 0.05 and $90 \%$ power to test $\mathrm{H}_{0}: \rho=0.5$ versus $\mathrm{H}_{1}: \rho=0.75$, a sample of 62 subjects was required. To compensate for a $10 \%$ attrition rate for any reason, the sample size was increased to 68 .

\section{Results}

\section{Translation and adaptation}

There was no discrepancy between the backwardtranslated English version of the self-rated FRQ and the original version. The self-rated FRQ was then presented to older adult osteoporotic patients to evaluate its understandability. From 15 randomly selected osteoporotic patients, none reported any difficulty in understanding the questions. No missing data were observed, and no patients offered any suggestion for improvement of the questionnaire. All 12 items on the self-rated FRQ had good content validity. One item (I often feel sad or depressed) had an index of item-objective congruence of 0.8 , whereas the other 11 items had an index of itemobjective congruence of 1.0. This version of the selfrated FRQ was evaluated for validation and reliability.

\section{Validation and reliability}

Eighty patients were screened during the study period. Twelve patients were excluded for the following reasons: 8 patients with severe cognitive and/or neurologic impairment, 3 patients with deafness, and 1 patient with severe cardiopulmonary disease that was considered to be at risk of sustaining harm during the performancebased tests. The remaining 68 patients were included. The mean age of study participants was 73.8 years (range: 65-88 years), and most subjects were female (91.2\%) (Table 1). Fifty-three patients $(77.9 \%)$ had a Charlson comorbidity index $\geq 3$. Thirty-four patients (50\%) had history of low-energy hip or vertebral compression fracture which occurred 2 or more years earlier.

Table 1 Patient demographic and clinical characteristics

\begin{tabular}{|c|c|c|c|c|}
\hline Patient characteristics & Total $(N=68)$ & Fracture group $(n=34)$ & Non-fracture group $(n=34)$ & $p$-value \\
\hline Age (years), mean $\pm S D$ & $73.8 \pm 6.2$ & $75.9 \pm 6.6$ & $71.7 \pm 5.1$ & 0.009 \\
\hline Female gender, n (\%) & $62(91.2 \%)$ & $28(82.4 \%)$ & $34(100.0 \%)$ & 0.025 \\
\hline Body mass index $\left(\mathrm{kg} / \mathrm{m}^{2}\right)$, mean $\pm \mathrm{SD}$ & $24.0 \pm 4.1$ & $24.5 \pm 4.4$ & $23.5 \pm 3.7$ & 0.334 \\
\hline \multicolumn{5}{|l|}{ Charlson comorbidity index (CCI), n (\%) } \\
\hline 2 & $15(22.1 \%)$ & $3(8.8 \%)$ & $12(35.3 \%)$ & \multirow[t]{2}{*}{0.008} \\
\hline$\geq 3$ & $53(77.9 \%)$ & $31(91.2 \%)$ & $22(64.7 \%)$ & \\
\hline \multicolumn{5}{|l|}{ Location of fracture, n(\%) } \\
\hline No fracture & $34(50.0 \%)$ & $0(0.0 \%)$ & $34(100.0 \%)$ & \multirow[t]{3}{*}{$<0.001$} \\
\hline Vertebral compression fracture & $23(33.8 \%)$ & $23(67.6 \%)$ & $0(0.0 \%)$ & \\
\hline Hip fracture & $11(16.2 \%)$ & $11(32.4 \%)$ & $0(0.0 \%)$ & \\
\hline \multicolumn{5}{|l|}{ Ambulatory status, n(\%) } \\
\hline Household & $4(5.9 \%)$ & $4(11.8 \%)$ & $0(0.0 \%)$ & \multirow[t]{2}{*}{0.114} \\
\hline Community & $64(94.1 \%)$ & $30(88.2 \%)$ & $34(100.0 \%)$ & \\
\hline \multicolumn{5}{|l|}{ Assisting device, n (\%) } \\
\hline Without assisting device & $59(86.8 \%)$ & $26(76.5 \%)$ & $33(97.1)$ & \multirow[t]{2}{*}{0.027} \\
\hline With assisting device & $9(13.2 \%)$ & $8(23.5 \%)$ & $1(2.9 \%)$ & \\
\hline \multicolumn{5}{|l|}{ Bone mineral density $\left(\mathrm{g} / \mathrm{cm}^{2}\right)$, mean $\pm \mathrm{SD}$} \\
\hline Lumbar spine & $0.888 \pm 0.177$ & $0.989 \pm 0.277$ & $0.856 \pm 0.118$ & 0.150 \\
\hline Femoral neck & $0.678 \pm 0.106$ & $0.672 \pm 0.118$ & $0.685 \pm 0.095$ & 0.636 \\
\hline Total hip & $0.745 \pm 0.118$ & $0.742 \pm 0.136$ & $0.749 \pm 0.098$ & 0.801 \\
\hline \multicolumn{5}{|l|}{ Type of anti-osteoporotic drug, n (\%) } \\
\hline Oral bisphosphonate & $44(64.7 \%)$ & $22(64.7 \%)$ & $22(64.7 \%)$ & \multirow[t]{3}{*}{1.000} \\
\hline Intravenous bisphosphonate & $6(8.8 \%)$ & $3(8.8 \%)$ & $3(8.8 \%)$ & \\
\hline Denosumab & 18 (26.5\%) & 9 (26.5\%) & 9 (26.5\%) & \\
\hline
\end{tabular}

A $p$-value $<0.05$ indicates statistical significance (Student's $t$-test) Abbreviation: SD Standard deviation 
Those patients were assigned to the fracture group, whereas patients without a history of fracture were allocated to the non-fracture group. Fifty-nine patients $(86.8 \%)$ walked without a gait aid, and the majority (94.1\%) were considered community-dwelling older adults who could ambulate outdoors independently.

The fracture group was significantly older $(p=0.009)$, had a significantly lower proportion of female patients $(p=0.025)$, and was significantly more likely to have a Charlson comorbidity index $\geq 3(p=0.008)$ compared to the non-fracture group. In addition, approximately onequarter of fracture group patients used a gait aid compared to only $2.9 \%$ in the non-fracture group $(p=0.027)$. There was no significant difference in bone mineral density, ambulatory status, or type of anti-osteoporotic drugs between groups.

The self-rated FRQ score and other outcome measurement scores were found not to be normally distributed (Kolmogorov-Smirnov test, $p<0.05$ ). Baseline outcome measurement scores compared between the fracture and non-fracture groups are shown in Table 2 . The median self-rated FRQ and Thai-FRAT scores were 6 and 3 points, respectively. When we compared patient scores between the fracture and non-fracture groups, the median self-rated FRQ score was significantly higher in those with a history of fracture ( 7 and 5 points for the fracture and non-fracture groups, respectively; $p=$ 0.009). The median Thai-FRAT scores for the fracture and non-fracture groups were 3 and 2.5 points, respectively. There was no difference in the Thai-FRAT scores between the fracture and non-fracture groups $(p=0.31)$. The median BBS score was 50 . The median time used to complete the TUG and 5TSTS tests was 13 and $16.2 \mathrm{~s}$, respectively. Similar to the self-rated FRQ, the scores of the BBS, TUG test, and 5TSTS test were all significantly different between the fracture and non-fracture groups (Table 2). Approximately $65 \%$ of patients were classified as being at high risk for falling based on the 4-point cutoff value for the self-rated FRQ (Fig. 1).

Our analysis to evaluate for construct validity is presented in Table 3. The correlations between the score of the self-rated FRQ and all other outcome measurements were statistically significant $(p<0.001)$. A moderately strong correlation was observed between the self-rated FRQ and the BBS, TUG test, and 5TSTS test $(|r|=0.69$, 0.535 , and 0.566 , respectively). The correlation between the self-rated FRQ and the Thai-FRAT was fair $(|r|=$ 0.487). When analyzing correlations within only the fracture group, we found moderately strong correlations between the score of the self-rated FRQ and the scores of the other outcome measurements $(|r|$ ranging from 0.503 to 0.658 ). In contrast, the correlations in the nonfracture group were lower with fair correlations between the self-rated FRQ and the Thai-FRAT, TUG, and 5TSTS ( $|r|$ ranging from 0.300 to 0.430$)$, and moderately strong correlation between the self-rated FRQ and the BBS $(|r|=0.658)$ (Table 3).

No floor or ceiling effects were observed in any of the 5 evaluated assessment tools. Test-retest reliability of the self-rated FRQ was high with a Kappa of 1 (see Additional file 1). Internal consistency of the self-rated FRQ was excellent with a Cronbach's alpha of 0.936.

\section{Discussion}

The most common cause of fracture in osteoporotic populations is falling from a standing height or less, and $79 \%$ of hip fractures result from a simple fall [24]. In the United States, fall-related deaths among patients aged over 65 years increased 31\% from 2007 to 2016, and falls are the leading cause of death from unintentional injuries in this population [25]. Therefore, fall risk reduction is an essential component of both primary and secondary fragility fracture prevention strategies, which are usually implemented via a multidimensional approach. Components of this strategy include calcium and vitamin D supplementation, exercise, medication review, anti-osteoporotic drugs, and fall risk assessment. Although a number of fall risk assessment tools have been developed to evaluate fall risk in older adult population, no single test can determine the risk of falls accurately. In this study, we demonstrated that the self-rated FRQ is a valid and reliable tool for assessing fall risk in older adult population with osteoporosis.

Osteoporosis is commonly diagnosed using BMD Tscore or by the occurrence of a fragility fracture [26]. However, these two diagnostic subgroups are different.

Table 2 Baseline patient scores for the 5 outcome measures compared between the fracture and non-fracture groups

\begin{tabular}{lllll}
\hline Outcome measure & Total score Median (IQR) & Fracture group Median (IQR) & Non-fracture group Median (IQR) & $\boldsymbol{p}$-value \\
\hline Self-rated FRQ & $6.0(2.0,8.0)$ & $7.0(3.0,9.0)$ & $5.0(1.8,7.0)$ & $\mathbf{0 . 0 0 9}$ \\
Thai-FRAT & $3.0(2.0,4.0)$ & $3.0(2.0,5.0)$ & $2.5(2.0,4.0)$ & 0.310 \\
BBS & $50.0(43.0,55.0)$ & $44.0(41.8,52.3)$ & $53.0(44.0,55.3)$ & $\mathbf{0 . 0 1 3}$ \\
TUG test & $13.0(10.6,16.2)$ & $13.9(11.7,21.7)$ & $11.5(10.4,13.7)$ & $\mathbf{0 . 0 0 5}$ \\
5TSTS test & $16.2(13.9,20.2)$ & $18.8(14.9,25.5)$ & $15.3(12.9,18.2)$ & $\mathbf{0 . 0 0 4}$ \\
\hline
\end{tabular}

A $p$-value $<0.05$ indicates statistical significance (Mann-Whitney $U$ test)

Abbreviations: IQR Interquartile range, Self-rated FRQ Self-rated Fall Risk Questionnaire, Thai-FRAT Thai Falls Risk Assessment Test, BBS Berg Balance Scale, TUG test Timed get-up-and-go test, 5TSTS test 5 times sit-to-stand test 


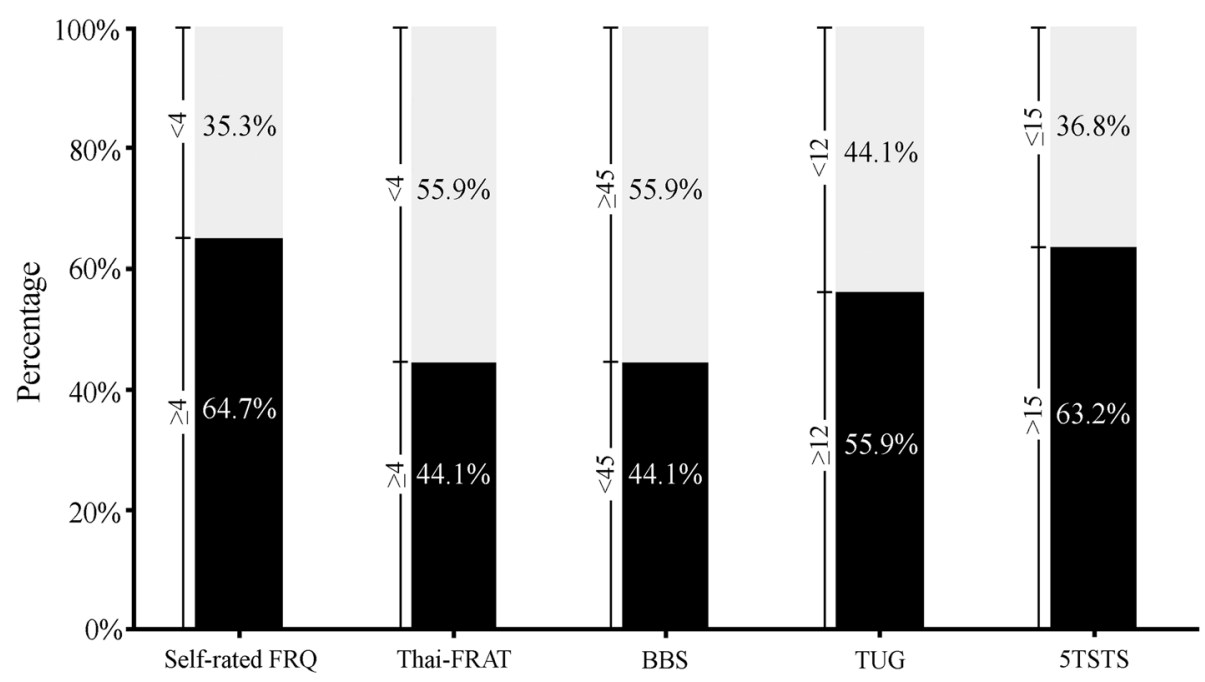

Low risk of falls

High risk of falls

Fig. 1 Percentage of patients classified as high-risk and low-risk of falls based on the cut-off value for each outcome measurement (Abbreviations: Self-rated FRQ, Self-rated Fall Risk Questionnaire; Thai-FRAT, Thai Falls Risk Assessment Test; BBS, Berg Balance Scale; TUG test, Timed get-up-and-go test; 5TSTS test, 5 times sit-to-stand test)

As shown in our study, patients in the fracture group were relatively older, had a higher Charlson comorbidity index, and had a higher number of patients who required a gait aid during ambulation. In addition, fracture patients had higher scores on the self-rated FRQ, and performed poorer on the performance-based tests. This may suggest that osteoporotic patients with a history of fragility fracture tend to be naturally more frail than those without fracture [27-29]. Fragility fracture can also adversely impact mobility, which leads to physical inactivity and further increases the risk of falls [30, 31]. Therefore, an attempt to reduce falls is of prime importance by identifying at-risk individuals, especially among those who have already sustained a fragility fracture.

Our findings showed that the self-rated FRQ demonstrated acceptable levels of validity and reliability for predicting falls in older adults with osteoporosis. The self-rated FRQ had moderately strong correlation with the performance-based tests, including BBS, TUG test, and 5TSTS test ( $|r|$ ranging from 0.535 to 0.690$)$. The previous study that evaluated the validity of another Thai-translated self-rated FRQ in community-dwelling older Thai adults found only fair correlation between their self-rated FRQ and the BBS and TUG $(|r|$ ranging from 0.330 to 0.499 ) [32]. This disparity in the degree of correlation may be attributable to differences in the study populations (community-dwelling older adults versus osteoporotic patients). When analyzing correlations between the self-rated FRQ and other fall risk assessment tests only in fracture patients, the strength of the correlations was stronger than in those who were diagnosed with osteoporosis from BMD alone. This suggests

Table 3 Construct validity of the self-rated FRQ relative to other outcome measurements

\begin{tabular}{|c|c|c|c|c|c|c|}
\hline \multirow{3}{*}{$\begin{array}{l}\text { Outcome } \\
\text { measurement } \\
\text { tool }\end{array}$} & \multicolumn{6}{|c|}{ Self-rated FRQ } \\
\hline & \multicolumn{2}{|c|}{ Total $(N=68)$} & \multicolumn{2}{|c|}{ Fracture group $(n=34)$} & \multicolumn{2}{|c|}{ Non-fracture group $(n=34)$} \\
\hline & $r$ & $p$-value & $r$ & $p$-value & $r$ & $p$-value \\
\hline Thai-FRAT & 0.487 & $<0.001$ & 0.503 & 0.002 & 0.430 & 0.011 \\
\hline BBS & -0.690 & $<0.001$ & -0.658 & $<0.001$ & -0.658 & $<0.001$ \\
\hline TUG test & 0.535 & $<0.001$ & 0.628 & $<0.001$ & 0.300 & 0.085 \\
\hline 5TSTS test & 0.566 & $<0.001$ & 0.646 & $<0.001$ & 0.386 & 0.024 \\
\hline
\end{tabular}

A $p$-value $<0.05$ indicates statistical significance (Spearman's rank correlation)

$r$ - Spearman's rank correlation coefficient

Abbreviations: Thai-FRAT Thai Falls Risk Assessment Test, BBS Berg Balance Scale, TUG test Timed get-up-and-go test, $5 T S T S$ test 5 times sit-to-stand test 
that the self-rated FRQ is more accurate in determining falls, especially among those with history of fragility fracture. It is clear that older adult patients with fragility fracture are at higher risk for falls compared to the general older adult population [4, 33]. Higher rates of subsequent falls are also frequently reported in osteoporotic patients [4, 34]. Moreover, osteoporotic patients are at greater risk for fractures than other healthy older adults due to lower bone strength [33]. Approximately 10-15\% of falls in patients aged over 65 years result in fractures [35], whereas osteoporotic patients sustained a rate of fall-related fractures of $40 \%$ [36]. Therefore, the selfrated FRQ should be implemented as part of a fall risk assessment test in osteoporotic patients, especially in those with fragility fracture.

A previous meta-analysis study showed performancebased tests to be the strongest predictor of falls [18]. The fact that the self-rated FRQ was found to be moderately strongly correlated with the three performancebased tests (BBS, TUG test, and 5TSTS test) used in this study suggests that the self-rated FRQ is an assessment tool that can reliably evaluate fall risk in older adults with osteoporosis. In addition, the fact that the self-rated FRQ significantly, but only fairly significantly, correlated with the Thai-FRAT, which consists mainly of questions specifically designed to identify fall risk factors, suggests that both share similar features only in some dimensions. The self-rated FRQ also has different ability to assess the physical performance of patients. Thus, the selfrated FRQ contains items that assess both physical performance and risk of falls in older adults with osteoporosis.

Although performance-based tests have been recommended by some investigators for their clinical usefulness in determining risk of falls in older adult patients [16-20], there are some disadvantages regarding the difficulty of administering these tests in real-life clinical settings, especially outpatient settings. Some physicians reported that in addition to performance-based tests being time-consuming, they also require specific knowledge and training to perform [37, 38]. Moreover, performance-based tests might not be suitable for some older adult patients, especially those with fragility fracture who are at high risk for falls [7]. To address these problems, most questionnaires were developed to include a number of fall-related factors [18, 39]; but still, those questionnaires do not contain questions that capture distinct domains of performance in activities of daily living. In other words, the actual level of patient functional ability contributes to different degrees of fallrelated injury, and the likelihood of falling hasn't been thoroughly assessed [40]. The simplicity, safety, ease of use, and the fact that it can be used in all osteoporotic patients, including those with fragility fractures, makes the self-rated FRQ an attractive fall risk assessment in this patient population. In addition, this self-screening tool will reduce assessment time for physicians, and it will not overburden patients. Lastly and importantly, the self-rated FRQ can be conveniently completed by the patient at home or in the waiting room.

The strength of this study is that it is the first study to evaluate the validity and reliability of the self-rated FRQ in osteoporotic patients. Since fall risk is higher in older adults with osteoporosis [3, 4], our self-rated FRQ, which is a simple, practical, and easy-to-conduct test, should be incorporated into routine clinical practice to predict the risk of falls. This study also has some mentionable limitations. First, the majority of our subjects were able to ambulate without gait aid; therefore, our results may not be generalizable to other populations, such as those who require a gait aid. The validity and reliability of this self-rated FRQ could be different if performed in those with physical limitations. Second, we assessed the validity of the self-rated FRQ via comparison with 3 performance-based tests because evidence supported the use of BBS, TUG, and 5TSTS tests as fall risk assessment tests in older adult population [18]. However, other performance-based tests are available, and we are not able to recommend which ones are best for evaluating fall risk in older adult patients with osteoporosis.

\section{Conclusions}

The self-rated FRQ is a valid and reliable tool for assessing the risk of falling in older adult patients with osteoporosis, including those with a history of fragility fracture. We also propose the use of the self-rated FRQ in the fracture liaison service to improve continuity of care in both primary and secondary prevention of fragility fractures.

\section{Supplementary Information}

The online version contains supplementary material available at https://doi. org/10.1186/s12891-020-03788-z.

Additional file 1: Supplementary table. Reliability of the self-rated fall risk questionnaire.

\section{Abbreviations}

Self-rated FRQ: Self-rated Fall Risk Questionnaire; Thai-FRAT: Thai Falls Risk Assessment Test; BBS: Berg Balance Scale; TUG test: Timed get-up-and-go test; 5TSTS test: 5 times sit-to-stand test; STEADI: Stop Elderly Accidents, Deaths, and Injuries

\section{Acknowledgements}

The authors gratefully acknowledge the patients that participated in this study; and, Ms. Wachirapan Narktang, Dr. Chulaluk Komoltri, and Mr. Suthipol Udompunthurak of the Faculty of Medicine Siriraj Hospital, Mahidol

University for their assistance with data collection and statistical analysis.

\section{Authors' contributions}

$\mathrm{NK}$ and $\mathrm{AU}$ contributed to conception and design of the study. NK and EV performed the data collection and the statistical analysis. NK and AU wrote 
the original draft, and all authors contributed to reviewing and editing the manuscript. All authors read and approved the final manuscript.

\section{Funding}

This was an unfunded study.

\section{Availability of data and materials}

The data collected and analyzed in the current study are available from the corresponding author on reasonable request.

\section{Ethics approval and consent to participate}

All procedures performed in studies involving human participants were in accordance with the ethical standards of the institutional and/or national research committee and with the 1964 Helsinki Declaration and its later amendments or comparable ethical standards. The questionnaire and methodology for this study was approved by the Siriraj Institutional Review Board (SIRB) of the Faculty of Medicine Siriraj Hospital, Mahidol University, Bangkok, Thailand (Number 749/2019). Written informed consent was obtained from individual participants included in this study.

\section{Consent for publication}

Not applicable.

\section{Competing interests}

All authors declare they have no competing interests.

Received: 29 June 2020 Accepted: 11 November 2020

\section{Published online: 18 November 2020}

\section{References}

1. $\mathrm{NIH}$, Consensus, Development, et al. Osteoporosis prevention, diagnosis, and therapy. Jama. 2001;285:785-95. https://doi.org/10.1001/jama.285.6.785.

2. Chapurlat RD, Bauer DC, Nevitt M, et al. Incidence and risk factors for a second hip fracture in elderly women. The study of osteoporotic fractures. Osteoporos Int. 2003;14:130-6. https://doi.org/10.1007/s00198-002-1327-6.

3. Liu-Ambrose T, Eng JJ, Khan KM, et al. Older women with osteoporosis have increased postural sway and weaker quadriceps strength than counterparts with normal bone mass: overlooked determinants of fracture risk? J Gerontol A Biol Sci Med Sci. 2003;58:M862-6. https://doi.org/10.1093/ gerona/58.9.m862.

4. Sinaki M, Brey RH, Hughes CA, et al. Balance disorder and increased risk of falls in osteoporosis and kyphosis: significance of kyphotic posture and muscle strength. Osteoporos Int. 2005;16:1004-10. https://doi.org/10.1007/ s00198-004-1791-2.

5. Center JR, Nguyen TV, Schneider D, et al. Mortality after all major types of osteoporotic fracture in men and women: an observational study. Lancet. 1999;353:878-82. https://doi.org/10.1016/s0140-6736(98)09075-8.

6. Peek-Asa C, Zwerling C. Role of environmental interventions in injury control and prevention. Epidemiol Rev. 2003;25:77-89. https://doi.org/10. 1093/epirev/mxg006.

7. Lloyd BD, Williamson DA, Singh NA, et al. Recurrent and injurious falls in the year following hip fracture: a prospective study of incidence and risk factors from the sarcopenia and hip fracture study. J Gerontol A Biol Sci Med Sci. 2009;64:599-609. https://doi.org/10.1093/gerona/glp003.

8. Perell $\mathrm{KL}$, Nelson A, Goldman RL, et al. Fall risk assessment measures: an analytic review. J Gerontol A Biol Sci Med Sci. 2001;56:M761-6. https://doi. org/10.1093/gerona/56.12.m761.

9. Howcroft J, Kofman J, Lemaire ED. Review of fall risk assessment in geriatric populations using inertial sensors. J Neuroeng Rehabil. 2013;10:91. https:// doi.org/10.1186/1743-0003-10-91.

10. Stevens JA, Phelan EA. Development of STEADI: a fall prevention resource for health care providers. Health Promot Pract. 2013;14:706-14. https://doi. org/10.1177/1524839912463576.

11. Rubenstein LZ, Vivrette R, Harker JO, et al. Validating an evidence-based, self-rated fall risk questionnaire (FRQ) for older adults. J Saf Res. 2011;42: 493-9. https://doi.org/10.1016/j.jsr.2011.08.006

12. Beaton DE, Bombardier C, Guillemin F, et al. Guidelines for the process of cross-cultural adaptation of self-report measures. Spine (Phila Pa 1976). 2000;25:3186-91. https://doi.org/10.1097/00007632-200012150-00014.
13. Phelan EA, Mahoney JE, Voit JC, et al. Assessment and management of fal risk in primary care settings. Med Clin North Am. 2015;99:281-93. https:// doi.org/10.1016/j.mcna.2014.11.004.

14. Vivrette RL, Rubenstein LZ, Martin $J$, et al. Development of a fall-risk selfassessment for community-dwelling seniors. J Aging Phys Act. 2011;19:1629. https://doi.org/10.1123/japa.19.1.16.

15. Thiamwong $L$, Thamarpirat J, Maneesriwongul $W$, et al. Thai falls risk assessment test (Thai-FRAT) developed for community-dwelling Thai elderly. J Med Assoc Thail. 2008;91:1823-31.

16. Bogle Thorbahn LD, Newton RA. Use of the berg balance test to predict falls in elderly persons. Phys Ther. 1996;76:576-83; discussion 84-5. https:// doi.org/10.1093/ptj/76.6.576.

17. Podsiadlo D, Richardson S. The timed "up \& go": a test of basic functional mobility for frail elderly persons. J Am Geriatr Soc. 1991;39:142-8. https:// doi.org/10.1111/j.1532-5415.1991.tb01616.x.

18. Lusardi MM, Fritz S, Middleton A, et al. Determining risk of falls in community dwelling older adults: a systematic review and meta-analysis using posttest probability. J Geriatr Phys Ther. 2017;40:1-36. https://doi.org/ 10.1519/jpt.0000000000000099.

19. Duncan RP, Leddy AL, Earhart GM. Five times sit-to-stand test performance in Parkinson's disease. Arch Phys Med Rehabil. 2011;92:1431-6. https://doi. org/10.1016/j.apmr.2011.04.008.

20. Buatois S, Miljkovic D, Manckoundia $\mathrm{P}$, et al. Five times sit to stand test is a predictor of recurrent falls in healthy community-living subjects aged 65 and older. J Am Geriatr Soc. 2008;56:1575-7. https://doi.org/10.1111/j.15325415.2008.01777.x

21. Chan YH. Biostatistics 104: correlational analysis. Singap Med J. 2003;44:614-

22. Sim J, Wright CC. The kappa statistic in reliability studies: use, interpretation, and sample size requirements. Phys Ther. 2005:85:257-68.

23. Terwee CB, Bot SD, de Boer MR, et al. Quality criteria were proposed for measurement properties of health status questionnaires. J Clin Epidemiol. 2007;60:34-42. https://doi.org/10.1016/j.jclinepi.2006.03.012.

24. Wongtriratanachai $P$, Luevitoonvechkij S, Songpatanasilp T, et al. Increasing incidence of hip fracture in Chiang Mai, Thailand. J Clin Densitom. 2013;16: 347-52. https://doi.org/10.1016/j.jocd.2012.07.002.

25. Burns E, Kakara R. Deaths from falls among persons aged $\geq 65$ years - United States, 2007-2016. MMWR Morb Mortal Wkly Rep. 2018;67:509-14. https:// doi.org/10.15585/mmwr.mm6718a1

26. Kanis JA. Assessment of fracture risk and its application to screening for postmenopausal osteoporosis: synopsis of a WHO report. WHO study group. Osteoporos Int. 1994;4:368-81. https://doi.org/10.1007/bf01622200.

27. Ensrud KE, Ewing SK, Taylor BC, et al. Frailty and risk of falls, fracture, and mortality in older women: the study of osteoporotic fractures. J Gerontol A Biol Sci Med Sci. 2007;62:744-51. https://doi.org/10.1093/gerona/62.7.744.

28. Haentjens P, Magaziner J, Colón-Emeric CS, et al. Meta-analysis: excess mortality after hip fracture among older women and men. Ann Intern Med. 2010;152:380-90. https://doi.org/10.7326/0003-4819-152-6-201003160-00008.

29. Li G, Thabane L, Papaioannou A, et al. An overview of osteoporosis and frailty in the elderly. BMC Musculoskelet Disord. 2017;18:46. https://doi.org/ 10.1186/s12891-017-1403-x.

30. Chu LW, Chiu AY, Chi I. Impact of falls on the balance, gait, and activities of daily living functioning in community-dwelling Chinese older adults. J Gerontol A Biol Sci Med Sci. 2006;61:399-404. https://doi.org/10.1093/ gerona/61.4.399.

31. Salpakoski A, Törmäkangas T, Edgren J, et al. Walking recovery after a hip fracture: a prospective follow-up study among community-dwelling over 60-year old men and women. Biomed Res Int. 2014;2014:289549. https://doi. org/10.1155/2014/289549.

32. Loonlawong $S$, Limroongreungrat $W$, Jiamjarasrangsi $W$. The stay independent brochure as a screening evaluation for fall risk in an elderly Thai population. Clin Interv Aging. 2019;14:2155-62. https://doi.org/10.2147/ cia.s233414.

33. Smulders E, van Lankveld W, Laan R, et al. Does osteoporosis predispose falls? A study on obstacle avoidance and balance confidence. BMC Musculoskelet Disord. 2011;12:1. https://doi.org/10.1186/1471-2474-12-1.

34. da Silva RB, Costa-Paiva L, Morais SS, et al. Predictors of falls in women with and without osteoporosis. J Orthop Sports Phys Ther. 2010;40:582-8. https:// doi.org/10.2519/jospt.2010.3239.

35. Nevitt MC, Cummings SR, Hudes ES. Risk factors for injurious fall: a prospective study. J Gerontol. 1991;46:M164-M70. 
36. Dontas IA, Yiannakopoulos CK. Risk factors and prevention of osteoporosisrelated fractures. J Musculoskelet Neuronal Interact. 2007;7:268-72.

37. Fortinsky RH, lannuzzi-Sucich M, Baker DI, et al. Fall-risk assessment and management in clinical practice: views from healthcare providers. J Am Geriatr Soc. 2004;52:1522-6. https://doi.org/10.1111/j.1532-5415.2004.52416.x.

38. Chou WC, Tinetti ME, King MB, et al. Perceptions of physicians on the barriers and facilitators to integrating fall risk evaluation and management into practice. J Gen Intern Med. 2006;21:117-22. https://doi.org/10.1111/j. 1525-1497.2005.00298.x.

39. Park SH. Tools for assessing fall risk in the elderly: a systematic review and meta-analysis. Aging Clin Exp Res. 2018;30:1-16. https://doi.org/10.1007/ s40520-017-0749-0.

40. Speechley $M$, Tinetti M. Falls and injuries in frail and vigorous community elderly persons. J Am Geriatr Soc. 1991;39:46-52. https://doi.org/10.1111/j. 1532-5415.1991.tb05905.x.

\section{Publisher's Note}

Springer Nature remains neutral with regard to jurisdictional claims in published maps and institutional affiliations.

Ready to submit your research? Choose BMC and benefit from:

- fast, convenient online submission

- thorough peer review by experienced researchers in your field

- rapid publication on acceptance

- support for research data, including large and complex data types

- gold Open Access which fosters wider collaboration and increased citations

- maximum visibility for your research: over $100 \mathrm{M}$ website views per year

At BMC, research is always in progress.

Learn more biomedcentral.com/submissions 